\title{
Avaliação das Equações de Predição das Exigências de Proteína para Matrizes Pesadas na Fase de Crescimento ${ }^{1}$
}

\author{
Rosemeire da Silva Filardi², Roberta Basaglia ${ }^{3}$, Carlos Bôa-Viagem Rabello ${ }^{4}$, Flavio Alves \\ Longo ${ }^{5}$, Nilva Kazue Sakomura ${ }^{6}$, Otto Mack Junqueira ${ }^{6}$
}

\begin{abstract}
RESUMO - Objetivou-se avaliar as equações para predição das exigências protéicas de matrizes pesadas em crescimento, desenvolvidas em estudos anteriores na Faculdade de Ciências Agrárias e Veterinárias da UNESP, Jaboticabal, tendo como padrão de comparação as recomendações estabelecidas pelo manual de criação da linhagem. Foram utilizadas 288 matrizes pesadas da linhagem Hubbard Hy-Yield, com cinco semanas de idade, em delineamento inteiramente casualizado, com dois tratamentos e seis repetições, sendo 24 aves por unidade experimental até 14 semanas e, de 15 a 20 semanas de idade, 20 aves por unidade experimental. Um tratamento foi representado pelas recomendações protéicas para a linhagem (testemunha) e o outro pelas seguintes equações de predição das exigências de proteína: de 5 a 8 semanas - PB (g/ave/dia) = 2,02.P0,75+ 0,350.G, 9 a 14 semanas - PB = 2,02.P.75 + 0,406.G e de 15 a 20 semanas - PB = 2,02.P $\mathrm{P}^{0,75}+$ 0,463.G, em que P é o peso corporal (kg) e G, o ganho de peso diário (g). Os resultados indicaram que as equações de predição para proteína, apesar de não comprometerem o peso ou a uniformidade corporal em relação ao tratamento testemunha, determinaram menor porcentagem de peito e maior de gordura abdominal e maior teor de gordura na carcaça, sendo atribuído à menor ingestão de proteína proporcionada pelas equações de predição e, conseqüentemente, deficiência em relação a alguns aminoácidos que não foram suplementados.
\end{abstract}

Palavras-chave: desempenho de matrizes pesadas em crescimento, método fatorial

\section{Evaluation of the Prediction Equations of the Protein Requirements for Broiler Breeder Pullets}

\begin{abstract}
The objective of this research was to evaluate the prediction equations of the protein requirements for broiler breeder pullets, that was previously determined at Faculdade de Ciências Agrárias e Veterinárias - UNESP - Jaboticabal. The equations were compared with standard recommendation for the used strain. Two hundred and eighty eight broiler breeder pullets for Hubbard Hy-Yield strain at 5 weeks old were assigned to a randomized design with two treatments and six replication of 24 pullets until 14 weeks and 20 pullets from 14 to 20 weeks old. One treatment was represented by the protein standard recommendation for the strain (control) and another by the following prediction equations: from 5 to 8 weeks $-\mathrm{CP}(\mathrm{g} / \mathrm{bird} / \mathrm{day})=2.02 . \mathrm{W}^{\cdot 75}+.350 . \mathrm{G}$, from 9 to 14 weeks $-\mathrm{CP}=$ 2.02. $\mathrm{W}^{.75}+0,406 . \mathrm{G}$ and from 15 to 20 weeks old $-\mathrm{CP}=2.02$. W. ${ }^{.75}+0.463 . \mathrm{G}$, where $\mathrm{P}$ is body weight $(\mathrm{kg})$ and $\mathrm{G}$ is daily weight gain (g). The prediction equations for protein, in spite not affect the body weight and uniformity, but they promoted smaller breast percentage, higher abdominal fat percentage and fat in carcass. This result is attributed to the low protein intake determined by the prediction equations, and consequently deficiency in some amino acids that were not possible to add to the diets.
\end{abstract}

Key Words: broiler breeder pullets performance, factorial method

\section{Introdução}

Das pesquisas direcionadas à nutrição de matrizes de corte, o número de trabalhos envolvendo determinações das exigências nutricionais na fase de crescimento é muito restrito, sendo em sua maioria conduzidos na fase de produção (NRC, 1994). Porém, para obtenção de resultados satisfatórios na fase de produção, é necessário bom entendimento do reflexo do manejo nutricional na fase de crescimento sobre as características produtivas e reprodutivas, tendo em vista que o período de crescimento é a fase em que ocorrerá a formação da futura reprodutora, sendo o peso corporal, e mais especificamente a composição corporal, que irão definir o potencial de produção da ave (Boni, 1993).

\footnotetext{
${ }_{1}^{1}$ Parte da Tese de Doutorado da primeira autora e parte de Projeto Temático financiado pela FAPESP.

${ }^{2}$ Pós-doutoranda Bolsista da FAPESP na FCAV-UNESP - Jaboticabal (rofilardi@zipmail.com.br). Autor para correspondências.

3 Doutora em Zootecnia pela FCAV-UNESP - Jaboticabal (roberta@microsoft.com).

${ }^{4}$ Professor da UFRPE (cbviagem@ufrpe.br).

${ }^{5}$ Doutor em Zootecnia pela ESALQ - USP - Piracicaba (falongo@yahoo.com).

${ }^{6}$ Professor do Departamento de Zootecnia da FCAV-UNESP-Jaboticabal (sakomura@fcav.unesp.br; ottomack@fcav.unesp.br).
} 
Pesquisas relacionadas à determinação das exigências de proteína para aves em crescimento, principalmente matrizes pesadas, são limitadas, dando maior enfoque aos níveis de proteína nas dietas, que são bastante variados. De acordo com o NRC (1994), os níveis de proteína nas dietas para matrizes em crescimento são de 17, 15 e 14\% de PB para as idades de 0 a 6,6 a 12 e 12 a 18 semanas de idade, respectivamente, enquanto Leeson \& Summers (1997) estabelecem apenas dois níveis (18\% de PB para a fase inicial e $16 \%$ de PB para a fase de crescimento).

Em diversos experimentos (Leeson \& Summers, 1984; Bowmaker \& Gous, 1989; Lilburn \& NgiamRilling, 1990), foram testados diferentes níveis de proteína nas dietas de crescimento para matrizes pesadas, com o objetivo de medir o efeito sobre o crescimento e o desempenho na fase de reprodução. Entretanto, a ingestão de proteína parece estar mais relacionada ao crescimento das aves até cerca de quatro semanas de idade, uma vez que a partir deste período a ingestão de proteína parece não afetar o peso corporal (Lilburn et al., 1989).

Assim, as necessidades de proteína ou ingestão de proteína para matrizes pesadas em crescimento é um assunto controverso, visto que alguns estudos indicam que a ingestão de proteína não afeta o peso corporal, porém influi no desempenho na fase de reprodução.

De acordo com Bowmaker \& Gous (1989), para atendimento de suas necessidades de mantença e ganho de peso, matrizes pesadas a partir de 18 semanas de idade devem ingerir $10 \mathrm{~g}$ de proteína/dia, enquanto os estudos de Walsh \& Brake (1997) indicam que aves ingerindo menos que 1180 g de proteína até 20 semanas de idade, apesar de alcançarem peso corporal satisfatório, apresentaram posteriormente fertilidade reduzida.

De acordo com Hurwitz et al. (1978), a forma mais precisa para estabelecer as exigências de proteína se baseia no método fatorial, que consiste em determinar as necessidades de proteína considerando a soma das necessidades para mantença e crescimento.

Com base no conhecimento das necessidades para mantença e crescimento e/ou produção são elaboradas equações para predição das exigências diárias de determinado nutriente, prática adotada para atendimento das exigências energéticas de matrizes e poedeiras na fase de produção (Rostagno et al., 1983; Sakomura et al., 1993; NRC, 1994). As equações de predição levam em consideração fatores como peso corporal, ganho diário de peso e temperatura ambiente, permitindo o fornecimento do nutriente para o atendimento adequado das exigências relacionadas à mantença e ao crescimento da ave.

Com base no método fatorial, Silva-Filardi et al. (2000) desenvolveram equações de predição das exigências protéicas para matrizes pesadas em crescimento. Entretanto, como salienta Sakomura (1996), antes de indicar o uso destas equações, é importante testar sua validade e, se necessário, realizar ajustes para que as mesmas reflitam a real necessidade das aves.

Assim, o objetivo do presente estudo foi avaliar as equações de predição das exigências protéicas de matrizes pesadas em crescimento, desenvolvidas em estudos anteriores (Silva-Filardi et al., 2000), tendo como padrão para comparação as recomendações comerciais estabelecidas pelo manual de criação da linhagem utilizada.

\section{Material e Métodos}

Foram utilizadas 288 matrizes pesadas da linhagem Hubbard Hy-Yield, com cinco semanas de idade, sendo 24 aves por unidade experimental até 14 semanas e, a partir desta, até as 20 semanas de idade, 20 aves por unidade experimental. As aves foram alojadas em boxes de $6 \mathrm{~m}^{2}$, com divisórias teladas, possuindo um bebedouro pendular e dois comedouros tubulares.

As aves foram alimentadas até as 17 semanas no esquema de arraçoamento em dias alternados e, posteriormente, passaram ao esquema cinco dias-sim/ dois dias-não, no qual permaneceram até as 20 semanas de idade.

O delineamento experimental foi inteiramente casualizado, com dois tratamentos, seis repetições e 24 aves por unidade experimental. O tratamento testemunha foi representado pelas recomendações do manual de criação das aves, que proporcionou fornecimento de determinada quantidade de ração (com nível fixo de proteína de 16\%). No tratamento da equação de PB, foi fornecida a mesma quantidade de ração do tratamento testemunha, porém com o nível protéico da dieta determinado em função da exigência diária do nutriente, que foi obtida semanalmente aplicando-se o peso corporal real das aves e ganho de peso esperado (preconizado para linhagem) nas equações de predição das exigências 
de PB, determinadas por Silva-Filardi et al. (2000): 5 a 8 semanas: $\mathrm{PB}$ (g/ave/dia) $=2,02 . \mathrm{P}^{0,75}+0,350 . \mathrm{G} ; 9$ a 14 semanas: $P B(g /$ ave/dia $)=2,02 \cdot P^{0,75}+0,406 . G$; 15 a 20 semanas: $\mathrm{PB}$ (g/ave/dia) $=2,02 \cdot \mathrm{P}^{0,75}+$ 0,463.G, em que P é o peso corporal real (kg) e G, o ganho de peso diário esperado (g).

A aplicação das equações de predição de proteína determinaram diferentes exigências e, conseqüentemente, dietas com níveis variados de PB. Na Tabela 1, são apresentados os pesos corporais no início de cada semana e os ganhos de peso diários esperados (estimados em função do peso corporal indicado para a semana seguinte como ideal para a linhagem), bem como as exigências de proteína, consumo diário de ração e os níveis de proteína das dietas para o tratamento das equações de proteína. Como efeito ilustrativo nas figuras, foi inserido os valores de peso corporal e ingestão de proteína indicados como padrão para linhagem, sendo os dados fornecidos pela empresa que comercializa a linhagem.

Para formular as rações com baixos teores de proteína, foram utilizados farelo de trigo e farinha de mandioca (1,7\% de PB) e suplementação com DLmetionina, L-lisina, L-arginina, L-treonina eL-triptofano. A deficiência dos demais aminoácidos não foi corrigida em função da inviabilidade econômica. A composição percentual para as rações utilizadas na 5aㅡ, 10 $0^{\underline{a}}, 15^{\underline{a}}$ e $20^{\underline{a}}$ semanas são apresentadas na Tabela 2 .

Durante o período experimental, a cada semana foram controlados em todas as unidades experimentais o peso corporal médio, ganho de peso e consumo de ração. O peso corporal médio foi obtido pesando-se individualmente $50 \%$ de cada unidade experimental (sempre as mesmas aves). Porém, ao final da 8aㅗ $14^{\text {a }}$ e 20 a semanas, todas as aves da unidade experimental foram pesadas individualmente.

Durante os períodos de 5 a 8, 9 a 14 e 15 a 20 semanas de idade, foram avaliados o peso corporal, os consumos acumulados de ração e de proteína e a uniformidade corporal. A uniformidade corporal foi obtida considerando-se um coeficiente de variação de $10 \%$ e, como às 14 semanas de idade a uniformidade ficou abaixo do indicado (80\%), foram retiradas quatro aves por parcela, que representavam os extremos de peso corporal.

Ao final da $20^{\underline{a}}$ semana de idade, após 24 horas de jejum, foram abatidas quatro aves de cada parcela, sendo duas para análise da composição corporal (sem penas) em relação aos teores de água, proteína, extrato etéreo e cinzas e duas para avaliar as porcentagem de peito, de gordura abdominal e de penas. As porcentagens de peito, gordura abdominal

Tabela 1 - Valores de peso corporal (PC) e ganho de peso diário esperado (GPDE) aplicados nas equações de predição, exigências de proteína (EPB), consumo diário de ração (CDR) e níveis de proteína bruta das rações (PB) a cada semana

Table 1 - Values of body weight (BW) and expected daily weight gain (PDWG) used in the prediction equations, crude protein requirements (CPR), daily feed intake (DFI) and protein levels in the diet (CP), at each week

\begin{tabular}{cccccc}
\hline $\begin{array}{c}\text { Idade(semanas) } \\
\text { Age (weeks) }\end{array}$ & PC $(\mathrm{g})$ & $\mathrm{GPD}(\mathrm{g})$ & $\mathrm{EPB}(\mathrm{g} /$ dia $)$ & $\begin{array}{c}\text { CDR }(\mathrm{g}) \\
\text { DFI }(\mathrm{g} / \text { day })\end{array}$ & $\begin{array}{c}\text { PB na dieta }(\%) \\
\text { CP in the diet }(\%)\end{array}$ \\
\hline 5 & 371 & 18,4 & 7,4 & 36 & 20,6 \\
6 & 476 & 16,4 & 6,9 & 45 & 15,3 \\
7 & 582 & 15,6 & 4,5 & 45 & 15,1 \\
8 & 674 & 17,0 & 7,5 & 47 & 15,9 \\
\hline 9 & 803 & 7,7 & 4,9 & 51 & 9,5 \\
10 & 880 & 10,7 & 6,1 & 54 & 11,4 \\
11 & 991 & 7,7 & 5,1 & 55 & 9,4 \\
12 & 1065 & 10,1 & 6,2 & 58 & 10,8 \\
13 & 1176 & 7,3 & 5,2 & 60 & 8,7 \\
14 & 1250 & 9,7 & 6,3 & 63 & 10,0 \\
\hline 15 & 1333 & 8,6 & 6,5 & 67 & 9,7 \\
16 & 1440 & 8,6 & 6,6 & 75 & 8,8 \\
17 & 1544 & 6,7 & 5,9 & 80 & 7,4 \\
18 & 1672 & 6,0 & 5,7 & 82 & 7,0 \\
19 & 1746 & 10,3 & 7,6 & 88 & 8,9 \\
20 & 1873 & 8,4 & 7,1 & 94 & 7,6 \\
\hline
\end{tabular}

R. Bras. Zootec., v.33, n.4, p.901-910, 2004 
Tabela 2 - Composições percentuais e calculadas das dietas experimentais utilizadas na $5^{\mathrm{a}}, 10^{\mathrm{a}}, 15^{\mathrm{a}}$ e $20^{\mathrm{a}}$ semanas

Table 2 - Compositions of experimental diets used at the $5^{\text {th }}, 10^{\text {th }}, 15^{\text {th }}$ and $20^{\text {th }}$ week

\begin{tabular}{|c|c|c|c|c|}
\hline $\begin{array}{l}\text { Ingredientes (\%) } \\
\text { Ingredients }\end{array}$ & $\begin{array}{l}5^{\mathrm{a}} \text { semana } \\
5^{\text {th }} \text { week }\end{array}$ & $\begin{array}{l}10^{\mathrm{a}} \text { semana } \\
10^{\text {th }} \text { week }\end{array}$ & $\begin{array}{l}15^{\mathrm{a}} \text { semana } \\
15^{\text {th }} \text { week }\end{array}$ & $\begin{array}{c}20^{\mathrm{a}} \text { semana } \\
20^{\text {th }} \text { week }\end{array}$ \\
\hline $\begin{array}{l}\text { Milho } \\
\text { Corn }\end{array}$ & 62,842 & 73,952 & 74,147 & 71,163 \\
\hline $\begin{array}{l}\text { Farelo de soja } \\
\text { Soybean meal }\end{array}$ & 32,541 & 5,743 & 4,447 & 1,500 \\
\hline $\begin{array}{l}\text { Farinha de mandioca } \\
\text { Manioc flour }\end{array}$ & 0,000 & 0,000 & 0,000 & 12,000 \\
\hline $\begin{array}{l}\text { Farelo trigo } \\
\text { Wheat bran }\end{array}$ & 0,000 & 14,623 & 15,530 & 0,000 \\
\hline $\begin{array}{l}\text { Fosfato bicálcico } \\
\text { Dicalcium phosphate }\end{array}$ & 1,591 & 1,569 & 1,566 & 1,839 \\
\hline $\begin{array}{l}\text { Calcário calcítico } \\
\text { Limestone }\end{array}$ & 1,262 & 1,477 & 1,488 & 1,362 \\
\hline $\begin{array}{l}\text { Óleo de soja degomado } \\
\text { Soybean oil }\end{array}$ & 0,531 & 0,176 & 0,251 & 1,022 \\
\hline $\begin{array}{l}\text { Sal comum } \\
\text { Salt }\end{array}$ & 0,350 & 0,381 & 0,383 & 0,407 \\
\hline $\begin{array}{l}\text { Suplemento mineral + vitamínico } \\
\text { Mineral + vitamin supplement }\end{array}$ & 0,750 & 0,750 & 0,750 & 0,750 \\
\hline $\begin{array}{l}\text { DL-Metionina }(98 \%) \\
\text { DL-methionine }\end{array}$ & 0,133 & 0,309 & 0,321 & 0,462 \\
\hline $\begin{array}{l}\text { L-lisina } \\
\text { L-Lysine }\end{array}$ & 0,000 & 0,432 & 0,472 & 0,727 \\
\hline $\begin{array}{l}\text { L-Arginina } \\
\text { L-Arginine }\end{array}$ & 0,000 & 0,348 & 0,381 & 0,666 \\
\hline $\begin{array}{l}\text { L-Treonina } \\
\text { L-Threonine }\end{array}$ & 0,000 & 0,177 & 0,195 & 0,346 \\
\hline $\begin{array}{l}\text { L-Triptofano } \\
\text { L-Tryptophan }\end{array}$ & 0,000 & 0,062 & 0,069 & 0,124 \\
\hline $\begin{array}{l}\text { Areia lavada } \\
\text { Washed sand }\end{array}$ & 0,000 & 0,000 & 0,000 & 7,634 \\
\hline \multicolumn{5}{|c|}{$\begin{array}{l}\text { Composição calculada } \\
\text { Calculated composition }\end{array}$} \\
\hline $\begin{array}{l}\text { Energia metabolizável (kcal/kg) } \\
\text { Metabolizable energy }\end{array}$ & 2960 & 2960 & 2960 & 2960 \\
\hline $\begin{array}{l}\text { Proteína bruta (\%) } \\
\text { Crude protein }\end{array}$ & 20,600 & 11,400 & 9,700 & 7,600 \\
\hline $\begin{array}{l}\text { Cálcio (\%) } \\
\text { Calcium }\end{array}$ & 0,980 & 0,980 & 0,980 & 0,980 \\
\hline $\begin{array}{l}\text { Fósforo disponível (\%) } \\
\text { Available P }\end{array}$ & 0,410 & 0,410 & 0,410 & 0,410 \\
\hline $\begin{array}{l}\text { Sódio (\%) } \\
\text { Sodium }\end{array}$ & 0,182 & 0,178 & 0,178 & 0,178 \\
\hline $\begin{array}{l}\text { Metionina (\%) } \\
\text { Methionine }\end{array}$ & 0,470 & 0,522 & 0,528 & 0,604 \\
\hline $\begin{array}{l}\text { Metionina + Cistina (\%) } \\
\text { Met. + Cys. }\end{array}$ & 0,815 & 0,750 & 0,750 & 0,750 \\
\hline $\begin{array}{l}\text { Lisina }(\%) \\
\text { Lysine }\end{array}$ & 1,108 & 0,800 & 0,800 & 0,800 \\
\hline $\begin{array}{l}\text { Treonina (\%) } \\
\text { Threonine }\end{array}$ & 0,788 & 0,591 & 0,591 & 0,595 \\
\hline $\begin{array}{l}\text { Triptofano (\%) } \\
\text { Tryptophan }\end{array}$ & 0,269 & 0,183 & 0,183 & 0,183 \\
\hline $\begin{array}{l}\text { Arginina (\%) } \\
\text { Arginine }\end{array}$ & 1,327 & 0,996 & 0,996 & 0,996 \\
\hline $\begin{array}{l}{ }^{1} \text { Fornece por kilograma da dieta: } 8000 \\
\text { de riboflavina, } 0,25 \mathrm{mg} \text { de biotina, } 11,0 \\
\mathrm{mg} \text { de colina, } 1,5 \mathrm{mg} \text { de vitamina } \mathrm{K}, 1, \\
\mathrm{mg} \text { de zinco, } 5 \mathrm{mg} \text { de cobre, } 30 \mathrm{mg} \text { d } \\
1 \text { Provides per kilogram diet: vitamin } \mathrm{A}, 8000 \mathrm{U} \\
\text { acid, } 11.0 \mathrm{mg} \text {; vitamin } B_{12} \text {, } 13 \mathrm{ug} \text {; niacin, } 26 \\
\text { manganese, } 55 \mathrm{mg} \text {; zinc, } 50 \mathrm{mg} \text {; copper, } 5\end{array}$ & $\begin{array}{l}\text { I de vitamina A } \\
\text { g de ácido pan } \\
\mathrm{mg} \text { de Ácido fó } \\
\text { ferro, } 0,1 \mathrm{mg} \\
\text { jitamin } D, 1600 \mathrm{U} \\
\text { ig; choline, } 900 \text {, } \\
\text { g; iron, } 30 \mathrm{mg} \text {; }\end{array}$ & $\begin{array}{l}600 \mathrm{UI} \text { de vitam } \\
\text { tênico, } 13 \text { ug de } \\
\text { o, } 125 \mathrm{mg} \text { de al } \\
\text { selênio. } \\
\text { tamin } E, 11 \mathrm{mg} \text { rib } \\
\text { vitamin } K, 1.5 \mathrm{mg} \\
\text { nium, } 1 \mathrm{mg} \text {. }\end{array}$ & $\begin{array}{l}\text {, } 11 \mathrm{mg} \text { de } \\
\text { nina } \mathrm{B}_{12}, 26 \mathrm{r} \\
\text { dante, } 55 \mathrm{mg} \\
\text {, 9.0 mg; biotin } \\
\text { acid, } 1.5 \mathrm{mg} \text {; }\end{array}$ & $\begin{array}{l}\text { ina } E, 9,0 \mathrm{mg} \\
\text { e niacina, } 900 \\
\text { nanganês, } 50 \\
\text { mg; pantothenic } \\
\text { xidant, } 125 \mathrm{mg} \text {; }\end{array}$ \\
\hline
\end{tabular}

\section{R. Bras. Zootec., v.33, n.4, p.901-910, 2004}


e penas foram obtidas em relação ao peso de abate das aves. A gordura abdominal foi representada apenas pela gordura aderida ao papo, proventrículo e moela, em função da dificuldade para padronizar a retirada de gordura aderida nos demais compartimentos do trato gastrointestinal, o que poderia contribuir para um coeficiente ainda maior que o obtido.

\section{Resultados e Discussão}

Na Tabela 3, são apresentadas as médias para ingestão acumulada de proteína, para os períodos de 5 a 8, 9 a 14 e 15 a 20 semanas de idade e, na Figura 1, o comportamento semanal para ingestão de proteína. No período de 5 a 8 semanas de idade, os tratamentos não tiveram efeito $(\mathrm{P}>0,05)$ sobre a ingestão acumulada de proteína, o que já era esperado, em razão de a equação de $\mathrm{PB}$ ter proporcionado médio nível de proteína, próximo ao da dieta do tratamento testemunha (16\%). Para os períodos de 9 a 14, 15 a 20 e 5 a 20 semanas de idade, o uso da equação de $\mathrm{PB}$ proporcionou menor $(\mathrm{P}<0,01)$ ingestão acumulada de proteína em relação ao tratamento testemunha. Resultados semelhantes foram observados por Benatti (1998), em que frangas leves alimentadas de acordo com equações de predição das exigências de proteína também tiveram menor ingestão de proteína em relação ao tratamento testemunha, principalmente a partir de 13 semanas de idade.

Pouca ênfase é dada à ingestão de proteína bruta durante a fase de crescimento de matrizes pesadas, principalmente pelo fato de a ingestão deste nutriente estar mais relacionada ao crescimento das aves até aproximadamente quatro semanas de idade, sendo que, a partir deste período, a ingestão de proteína parece não afetar o peso corporal (Lilburn et al., 1989). Entretanto, Bowmaker \& Gous (1989) reportaram que matrizes pesadas a partir de 18 semanas de idade devem ingerir $10 \mathrm{~g}$ de proteína/dia para atendimento de suas necessidades de mantença e ganho de peso. Walsh \& Brake (1997) relataram ainda que aves que ingerem menos que $1180 \mathrm{~g}$ de proteína até 20 semanas de idade, apesar de atingirem peso corporal satisfatório, apresentam posteriormente uma reduzida fertilidade.

Considerando-se esses dados (Bowmaker \& Gous, 1989; Walsh \& Brake, 1997), o uso das equações de PB não proporcionou uma ingestão de $10 \mathrm{~g}$ de $\mathrm{PB} /$ dia a partir de 18 semanas (Figura 1 ) ou ingestão acumulada de pelo menos 1180 g de PB até 20 semanas de idade (Tabela 3), o que indica que a baixa ingestão de proteína, determinada pela aplicação das equações, pode ter ocasionado reflexo negativo no desenvolvimento das aves, o que pode ser constatado pelo peso corporal.

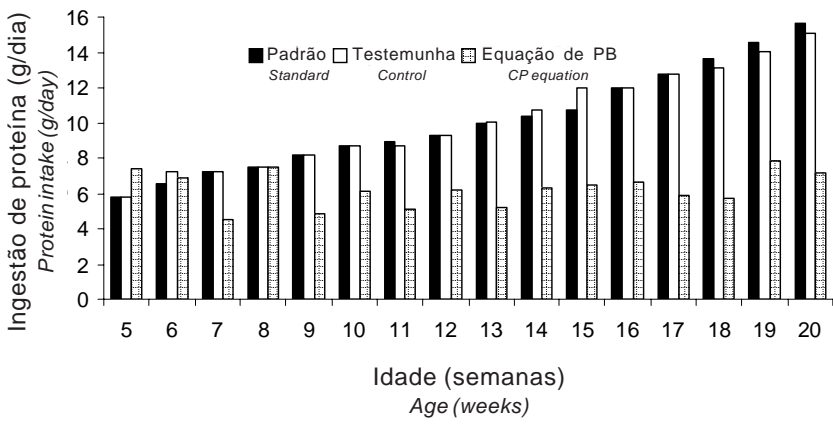

Figura 1 - Comportamento semanal para ingestão de proteína bruta.

Figure 1 - Weekly behavior for crude protein intake.

Tabela 3 - Médias de ingestão de proteína bruta acumulada nos períodos estudados Table3 - Means for accumulated crude protein intake at the studied periods

\begin{tabular}{lcccc}
\hline & \multicolumn{4}{c}{$\begin{array}{c}\text { Ingestão de proteína bruta acumulada (g/ave/período) } \\
\text { Accumulated crude protein intake (g/bird/day) }\end{array}$} \\
\cline { 2 - 5 } $\begin{array}{l}\text { Tratamentos } \\
\text { Treatments }\end{array}$ & $\begin{array}{c}\text { 5 a 8 semanas } \\
\text { 5 to 8 weeks }\end{array}$ & $\begin{array}{c}\text { 9 a 14 semanas } \\
\text { 9 to 14 weeks }\end{array}$ & $\begin{array}{c}15 \text { a 20 semanas } \\
15 \text { to 20 weeks }\end{array}$ & 5 a 20 semanas \\
\hline $\begin{array}{l}\text { Testemunha } \\
\text { Control }\end{array}$ & $195,5 \pm 0$ & $383,4 \pm 0$ & $532,8 \pm 0$ & $1111,7 \pm 0$ \\
$\begin{array}{l}\text { Equação PB } \\
\text { CP equation }\end{array}$ & $186,7 \pm 9,7$ & $240,8 \pm 27,9$ & $271,7 \pm 29,2$ & $699,2 \pm 37,3$ \\
\hline $\mathrm{F}$ & $4,91^{*}$ & $156,02^{* *}$ & $480,76^{* *}$ & $734,77^{* *}$ \\
\hline $\mathrm{CV}(\%)$ & 3,60 & 6,34 & 5,13 & 2,91 \\
\hline$* *(\mathrm{P}<0,01),{ }^{*}(\mathrm{P}<0,05)$. & & &
\end{tabular}

R. Bras. Zootec., v.33, n.4, p.901-910, 2004 
As médias para peso corporal às 8,14 e 20 semanas de idade são relacionadas na Tabela $4 \mathrm{e}$ Figura 2. Até 8 semanas de idade, o peso corporal não foi afetado pelos tratamentos $(\mathrm{P}>0,05)$. Entretanto, às 14 e 20 semanas de idade o uso das equações de $\mathrm{PB}$ proporcionou menor peso $(\mathrm{P}<0,01)$. $\mathrm{O}$ menor peso observado para o uso das equações de $\mathrm{PB}$ foi reflexo da menor ingestão de proteína apresentada por este tratamento (Tabela 3).

Com frangas de postura em crescimento, Benatti (1998) também observou que a menor ingestão de proteína não afetou o peso corporal das aves até 12 semanas. Entretanto, às 18 semanas de idade, a menor ingestão de proteína refletiu em menor peso corporal quando comparado ao peso de aves ingerindo a mesma quantidade de EM (kcal/dia), porém maiores quantidades de proteína. Por outro lado, este reflexo negativo da menor ingestão de proteína sobre o peso corporal não foi observado por Walsh \& Brake (1997), pois, em um dos experimentos, aves apresentando mesma ingestão de EM e ingestão acumulada até 20 semanas de 1032 e 1254 g de PB apresentaram peso corporal semelhante, 1950 e 1940g, respectivamente. Entretanto, a variação na ingestão de proteína foi relativamente pequena quando comparada à observada no presente estudo.

$O$ fato de o uso da equação de $\mathrm{PB}$ ter proporcionado peso corporal às 20 semanas inferior ao do tratamento testemunha não indica que a menor ingestão de proteína tenha comprometido o desempenho da ave, uma vez que, se considerado o peso de 1932 g preconizado para a idade, os pesos proporcionados por este tratamento (2032 g) e pelo tratamento testemunha (2100 g) foram superiores ao recomendado. O fato de as aves atingirem peso corporal satisfatório, embora com baixa ingestão de proteína, pode ser explicado pela manutenção dos níveis de aminoácidos na dieta, promovida pela suplementação com aminoácidos sintéticos, garantindo o atendimento às exigências em metionina, metionina+cistina, lisina, arginina, treonina e triptofano. Isto indica que a exigência de nitrogênio bruto ou proteína é baixa. Entretanto, o reflexo da menor ingestão de proteína pode afetar o desempenho na fase reprodutiva.

Scott et al. (1982), considerando uma dieta adequada em todos os aminoácidos essenciais, relaciona exigências mínimas de proteína bruta para frangas de reposição, em média de 7 e 6,5 g de proteína/dia, para as fases de 6 a 10 e 11 a 20

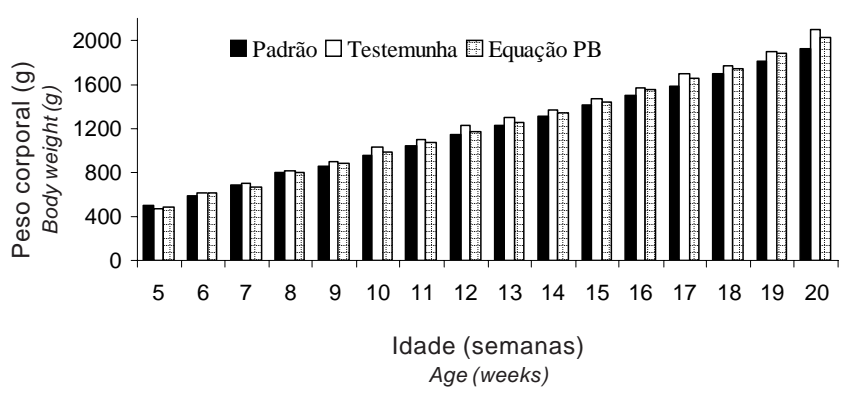

Figura 2 - Comportamento semanal para peso corporal de 5 a 20 semanas de idade.

Figure 2 - Weekly behavior for body weight from 5 to 20 weeks old.

Tabela 4 - Médias para peso corporal às 8, 14 e 20 semanas de idade Table 4 - Means for body weight at 8, 14 and 20 weeks old

\begin{tabular}{|c|c|c|c|}
\hline \multirow[b]{2}{*}{$\begin{array}{l}\text { Tratamento } \\
\text { Treatment }\end{array}$} & \multicolumn{3}{|c|}{$\begin{array}{l}\text { Peso corporal (g) } \\
\text { Body weight }(\mathrm{g})\end{array}$} \\
\hline & $\begin{array}{c}8 \text { semanas } \\
8 \text { weeks }\end{array}$ & $\begin{array}{c}14 \text { semanas } \\
14 \text { weeks }\end{array}$ & $\begin{array}{c}20 \text { semanas } \\
20 \text { weeks }\end{array}$ \\
\hline $\begin{array}{l}\text { Testemunha } \\
\text { Control }\end{array}$ & $821 \pm 18$ & $1374 \pm 16$ & $2100 \pm 31$ \\
\hline $\begin{array}{l}\text { Equação PB } \\
\text { CP equation }\end{array}$ & $803 \pm 18$ & $1333 \pm 25$ & $2032 \pm 33$ \\
\hline $\bar{F}$ & $3,17 \mathrm{NS}$ & $10,97 * *$ & $13,42 * *$ \\
\hline $\mathrm{CV}(\%)$ & 2,24 & 1,56 & 1,56 \\
\hline
\end{tabular}

NS - Não significativo $(P>0,05),{ }^{* *}(P<0,01)$.

Not significant effect $(P>$.05). 
semanas de idade, respectivamente. Os efeitos benéficos do atendimento às exigências de aminoácidos essenciais em dietas de baixa proteína também são relatados por Chi (1985).

Neste estudo, as baixas exigências de proteína estimadas pelas equações de predição e, conseqüentemente, os baixos níveis de proteína nas dietas são explicadas pelo fato de as aves se encontrarem acima do peso corporal, de maneira que o ganho de peso previsto utilizado na equação de predição foi inferior ao indicado pelo padrão da linhagem, o que refletiu em menores exigências para ganho de peso e menores níveis de PB nas dietas.

Na Tabela 5, são apresentadas as médias para uniformidade às 8,14 e 20 semanas de idade e na Figura 3, o comportamento semanal para este parâmetro. A uniformidade às 8 semanas de idade não diferiu entre os tratamentos $(\mathrm{P}>0,05)$, porém a equação de $\mathrm{PB}$ apresentou melhores resultados às 14 $(\mathrm{P}<0,01)$ e às 20 semanas de idade $(\mathrm{P}<0,05)$.

A maior uniformidade observada às 20 semanas de idade com o uso das equações de PB pode ter ocorrido também em função da retirada de quatro aves por parcela ao final da 14른 semana, para eliminar extremos, de forma que, se o tratamento testemunha já apresentava menor uniformidade, a tendência seria continuar apresentando esse menor valor em relação ao uso das equações, mesmo após a retirada das quatro aves que representavam os extremos.

Os resultados de uniformidade apresentados neste estudo discordam dos de Benatti (1998). O autor observa que a alimentação de frangas de postura, de acordo com equações de predição das exigências de

Tabela 5 - Médias para uniformidade às 8,14 e 20 semanas de idade

Table 5 - Means for uniformity at 8, 14 and 20 weeks old

\begin{tabular}{lccc}
\hline & \multicolumn{3}{c}{ Uniformidade (\%) } \\
Uniformity (\%) \\
\cline { 2 - 4 } Tratamento & 8 semanas & 14 semanas & 20 semanas \\
Treatment & 8 weeks & 14 weeks & 20 weeks \\
\hline Testemunha & $94,67 \pm 9,69$ & $61,50 \pm 7,82$ & $71,33 \pm 5,35$ \\
Control & & & \\
Equação PB & $96,00 \pm 4,38$ & $73,50 \pm 3,21$ & $83,50 \pm 10,84$ \\
CP equation & & & \\
\hline F & $0,09 \mathrm{NS}$ & $12,10 * *$ & $6,08^{*}$ \\
\hline CV(\%) & 7,89 & 8,85 & 11,09 \\
\hline
\end{tabular}

NS - Não significativo $(P>0,05),{ }^{* *}(P<0,01),{ }^{*}(P<0,05)$.

Not significant effect $(P>$.05).

R. Bras. Zootec., v.33, n.4, p.901-910, 2004 proteína bruta proporcionou menor uniformidade em relação à apresentada por aves alimentadas à vontade ou aves alimentadas de forma controlada, recebendo mesma quantidade de EM (kcal/dia) e maiores teores de proteína.

As médias para peso de abate, porcentagens de penas, de peito e de gordura abdominal às 20 semanas de idade são apresentadas na Tabela 6 . O peso ao abate e porcentagem de penas não foram afetados pelos tratamentos $(\mathrm{P}>0,05)$. Por outro lado, os dados de porcentagem de peito e de gordura abdominal foram significativamente afetados pelos tratamentos, sendo que o uso da equações de $\mathrm{PB}$ determinou menor porcentagem de peito $(\mathrm{P}<0,05)$ e maior de gordura abdominal $(\mathrm{P}<0,01)$.

A menor ingestão de proteína proporcionada pela utilização das equações de PB afetou negativamente as porcentagens de peito e de gordura abdominal. De forma semelhante, Lilburn et al. (1989), em estudo com matrizes pesadas entre 2 e 16 semanas de idade, observaram que a menor ingestão de proteína ocasionou diminuição no músculo pectoralis major e aumento na gordura abdominal. A diminuição da porcentagem de peito foi observada também em matrizes pesadas em reprodução, quando submetidas a dietas de baixa proteína (16, 14, 12 e 10\% de PB) suplementadas com aminoácidos sintéticos. Entretanto, nesse caso, a porcentagem de gordura abdominal não foi afetada (Lopez \& Leeson, 1995).

No presente estudo, a menor ingestão de proteína comprometeu a síntese protéica, desencadeando menor deposição de proteína muscular; conseqüentemente, a energia que seria destinada a

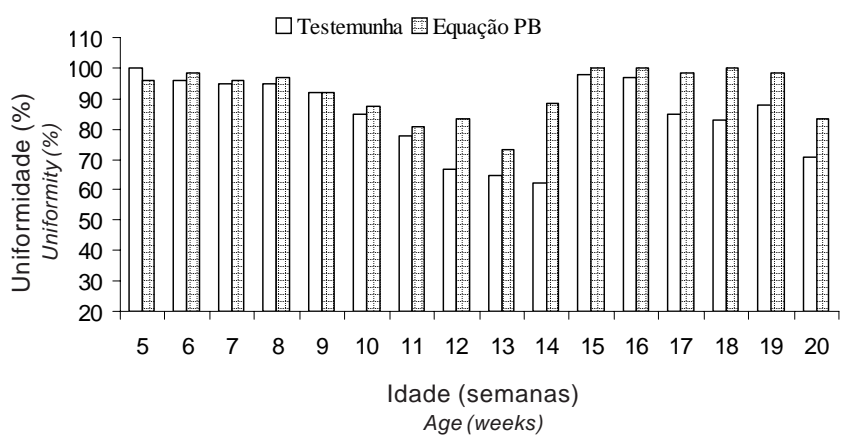

Figura 3 - Comportamento semanal para a uniformidade de 5 a 20 semanas de idade.

Figure 3 - Weekly behavior for body weight from 5 to 20 weeks old. 
essa função foi possivelmente desviada para o acúmulo de gordura abdominal. Provavelmente, a diminuição na síntese protéica tenha decorrido do não atendimento às exigências de alguns aminoácidos. Com exceção da metionina, lisina, treonina, triptofano e arginina, os demais aminoácidos não foram suplementados, o que pode ter comprometido o atendimento das exigências de fenilalanina, leucina, isoleucina, valina e histidina.

Os resultados de porcentagem de penas, embora não significativos, e os de peito e de gordura abdominal indicaram que, apesar de a utilização da equação de PB não ter prejudicado o peso corporal ou a uniformidade, causou prejuízos no empenamento, no tamanho de peito e provavelmente nas reservas para suportar o pico de produção, proporcionando ainda aumento na deposição de gordura abdominal, que representa efeito negativo na reprodução (McDaniel et al., 1981).

Em relação ao empenamento, embora a diferença entre os tratamentos não tenha sido significativa, ressalta-se que o uso das equações de PB determinou aves com penas de aspecto arrepiado e pouco sedoso em relação às penas das aves do tratamento testemunha, o que provavelmente tenha ocorrido pela deficiência de alguns aminoácidos. Esse prejuízo no empenamento, atribuído à deficiência de aminoácidos causada pelos baixos níveis de proteína na dieta, mesmo com a suplementação de alguns aminoácidos, também foi observado por Benatti (1998), em frangas de postura na fase de crescimento.

Na Tabela 7, são apresentados os resultados da análise de composição corporal às 20 semanas de idade. Para a porcentagem de proteína e de cinzas não foram observadas diferenças, em função dos tratamentos $(\mathrm{P}>0,05)$. Entretanto, os teores de água (menor) e gordura corporal (maior) foram proporcionados pelos tratamentos $(\mathrm{P}<0,01)$, com $\mathrm{o}$ uso das equações de PB.

As alterações na composição corporal, em função da menor ingestão de proteína, causaram aumento no teor de gordura, em decorrência de redução no teor de água, sem alterar, contudo, o teor de proteína. Segundo Leeson \& Summers (1984), a ingestão de proteína tem pouco efeito sobre o teor de proteína na carcaça.

Tabela 6 - Médias para peso de abate e porcentagens de penas, de peito e de gordura abdominal às 20 semanas de idade

Table 6 - Means for weight at slaughter and feather, breast and abdominal fat percentages at 20 weeks old

\begin{tabular}{lcccc}
\hline $\begin{array}{l}\text { Tratamento } \\
\text { Treatment }\end{array}$ & $\begin{array}{c}\text { Peso de abate }(\mathrm{g}) \\
\text { Weight at slaughter }\end{array}$ & $\begin{array}{c}\text { \% de penas } \\
\text { Feather \% }\end{array}$ & $\begin{array}{c}\text { \% de peito } \\
\text { Breast \% }\end{array}$ & $\begin{array}{c}\text { \% gordura abdominal } \\
\text { Abdominal fat \% }\end{array}$ \\
\hline $\begin{array}{l}\text { Testemunha } \\
\begin{array}{l}\text { Control } \\
\text { Equação PB } \\
\text { CP equation }\end{array}\end{array}$ & $1961 \pm 71$ & $5,46 \pm 0,87$ & $23,48 \pm 1,05$ & $0,71 \pm 0,35$ \\
\hline F & $1917 \pm 51$ & $4,40 \pm 1,36$ & $22,07 \pm 0,74$ & $2,41 \pm 0,60$ \\
\hline $\mathrm{CV}(\%)$ & $1,55 \mathrm{NS}$ & $2,56 \mathrm{NS}$ & $7,20^{*}$ & $35,75^{* *}$ \\
\hline
\end{tabular}

NS - Não significativo $(P>0,05),{ }^{* *}(P<0,01),{ }^{*}(P<0,05)$.

Not significant effect $(P>05)$.

Tabela 7 - Médias dos teores de água, proteína, gordura e cinzas na carcaça das aves às 20 semanas de idade

Table 7 - Means for water, protein, fat and ash in the carcass of pullets at 20 weeks old

\begin{tabular}{lcccc}
\hline $\begin{array}{l}\text { Tratamento } \\
\text { Treatment }\end{array}$ & $\begin{array}{c}\text { Água (\%) } \\
\text { Water (\%) }\end{array}$ & $\begin{array}{c}\text { Proteína (\%) } \\
\text { Protein (\%) }\end{array}$ & $\begin{array}{c}\text { Gordura (\%) } \\
\text { Fat (\%) }\end{array}$ & $\begin{array}{c}\text { Cinzas (\%) } \\
\text { Ash (\%) }\end{array}$ \\
\hline $\begin{array}{l}\text { Testemunha } \\
\text { Control }\end{array}$ & $69,45 \pm 0,43$ & $17,78 \pm 0,69$ & $9,65 \pm 0,78$ & $3,54 \pm 0,14$ \\
$\begin{array}{l}\text { Equação PB } \\
\text { CP equation }\end{array}$ & $65,69 \pm 1,63$ & $17,55 \pm 0,78$ & $13,73 \pm 1,23$ & $3,57 \pm 0,29$ \\
\hline F & $29,83^{* *}$ & $0,29 \mathrm{NS}$ & $46,95^{* *}$ & $0,08 \mathrm{NS}$ \\
\hline $\mathrm{CV}(\%)$ & 1,76 & 4,17 & 8,80 & 6,35 \\
\hline
\end{tabular}

NS - Não significativo $(P>0,05),{ }^{* *}(P<0,01)$.

Not significant effect $(P>05)$.

R. Bras. Zootec., v.33, n.4, p.901-910, 2004 
O aumento do teor de gordura na carcaça e o efeito da alimentação com dietas de baixa proteína, suplementadas por aminoácidos sintéticos, foi também observado por Lopez \& Leeson (1995) em matrizes pesadas alimentadas de 18 a 55 semanas de idade com dietas contendo 16, 14, 12 e 10\% de PB. Em estudos com frangos, Rosebrough et al. (1987) demonstraram que os níveis mais baixos de proteína na dieta estão relacionados com maior taxa de lipogênese e, conseqüentemente, maior deposição de gordura na carcaça, o que também foi observado no presente estudo, em matrizes pesadas em crescimento ingerindo menores quantidades de proteína.
Na Tabela 8, são apresentadas as porcentagens médias de proteína destinadas à mantença e ao ganho de peso diário em relação ao total de proteína preconizado pelas equações e o comportamento do ganho de peso diário em relação ao utilizado como referência (padrão da linhagem) para cálculo das exigências diárias de ganho de peso.

Os dados apresentados na Tabela 8 indicam que, de acordo com as equações de predição para proteína, a proporção de proteína para mantença aumenta com a idade enquanto a proporção para ganho de peso diminui, sendo que até 14 semanas de idade a mantença representou, em média, 30\% da ingestão total de

Tabela 8 - Médias semanais para ganho de peso proposto (GPP) e real (GPR), diferença entre ganho real e proposto, PB para mantença $(\mathrm{PBm})$, PB para ganho de peso $(\mathrm{PBg})$ e porcentagens de PB para mantença e ganho em relação ao total de PB preconizado pelas equações

Table 8 - Weekly Means for proposed (PWG) and real weight gain (RWG), difference between real and proposed weight gain, $\mathrm{CP}$ for maintenance $(\mathrm{CPm}), \mathrm{CP}$ for weight gain $(\mathrm{CPg})$ and percentages for $C P$ for maintenance and gain in relation to total crude protein preconized by equation

\begin{tabular}{|c|c|c|c|c|c|c|c|}
\hline $\begin{array}{c}\text { Idade } \\
\text { (sem) } \\
\text { Age } \\
\text { (weeks) }\end{array}$ & $\begin{array}{c}\mathrm{GPP}^{1} \\
\text { (g/dia) } \\
P W G \\
\text { (g/day) }\end{array}$ & $\begin{array}{c}\mathrm{GPR}^{2} \\
\text { (g/dia) } \\
R W G \\
\text { (g/day) }\end{array}$ & $\begin{array}{c}\text { Diferença } \\
\text { (GPR-GPP) } \\
\text { Difference } \\
\text { (RWG-PWG) }\end{array}$ & $\begin{array}{c}\mathrm{PBm}^{3} \\
\text { (g/dia) } \\
\mathrm{CPm} \\
\text { (g/day) }\end{array}$ & $\begin{array}{c}\mathrm{PBg}^{4} \\
\text { (g/dia) } \\
\mathrm{CPg} \\
\text { (g/day) }\end{array}$ & $\begin{array}{c}\text { \%PB } \\
\text { Mantença } \\
\% C P \\
\text { Maintenance }\end{array}$ & $\begin{array}{c}\text { \%PB } \\
\text { Ganho } \\
\% C P \\
W G\end{array}$ \\
\hline 5 & 16 & 13 & -3 & 1,08 & 5,45 & 17 & 83 \\
\hline 6 & 16 & 20 & 4 & 1,29 & 5,62 & 19 & 81 \\
\hline 7 & 9 & 8 & -1 & 1,46 & 3,06 & 32 & 68 \\
\hline 8 & 17 & 18 & 1 & 1,61 & 5,93 & 21 & 79 \\
\hline $\begin{array}{l}\text { Média } \\
\text { Mean } \\
5 \text { - } 8\end{array}$ & & & 1 & & & 22 & 78 \\
\hline 9 & 9 & 11 & 3 & 1,78 & 3,57 & 33 & 67 \\
\hline 10 & 11 & 16 & 5 & 1,92 & 4,26 & 31 & 69 \\
\hline 11 & 8 & 10 & 3 & 2,06 & 3,06 & 40 & 60 \\
\hline 12 & 10 & 16 & 6 & 2,20 & 4,12 & 35 & 65 \\
\hline 13 & 7 & 11 & 3 & 2,34 & 2,88 & 45 & 55 \\
\hline 14 & 10 & 13 & 3 & 2,45 & 3,90 & 39 & 61 \\
\hline $\begin{array}{l}\text { Média } \\
\text { Mean } \\
9-14\end{array}$ & & & 4 & & & 37 & 63 \\
\hline 15 & 10 & 14 & 4 & 2,59 & 4,45 & 37 & 63 \\
\hline 16 & 9 & 16 & 7 & 2,73 & 3,98 & 41 & 59 \\
\hline 17 & 6 & 18 & 13 & 2,90 & 2,63 & 52 & 48 \\
\hline 18 & 4 & 10 & 6 & 3,03 & 1,62 & 65 & 35 \\
\hline 19 & 10 & 21 & 11 & 3,17 & 4,66 & 40 & 60 \\
\hline 20 & 6 & 20 & 14 & 3,35 & 2,61 & 56 & 44 \\
\hline $\begin{array}{l}\text { Média } \\
\text { Mean } \\
15-20\end{array}$ & & & 9 & & & 49 & 51 \\
\hline
\end{tabular}

${ }_{1}^{1}$ GPP $=$ ganho de peso diário proposto para a linhagem ( $P$ WG = proposed daily weight gain to the strain).

$2 \mathrm{GPR}=$ ganho de peso real observado nas aves ( $R W G=$ real weight gain observed in the birds).

${ }^{3} \mathrm{PBm}=2,02 \cdot \mathrm{P}^{0,75}, \mathrm{P}=$ peso corporal $(\mathrm{kg})\left(\mathrm{CPm}=2,02 \cdot \mathrm{BW}^{0,75}, \mathrm{~W}=\right.$ body weight $(\mathrm{kg})$.

${ }^{4} \mathrm{PBg}=0,350 . \mathrm{G}$ (5 à 8 semanas); $\mathrm{PBg}=0,406 . \mathrm{G}$ (9 à 14 semanas) e $\mathrm{PBg}=0,463 . \mathrm{G}$ (14 à 20 semanas).

$C P g=.350 G$ (5 at 8 weeks); CPg =.406G (9 at 14 weeks) and CPg $=.463 G$ (14 at 20 weeks). 
proteína preconizada pelas equações. De acordo com Hurwitz \& Bornstein (1973), em aves em crescimento as exigências de proteína para mantença representam de 25 a 30\% das exigências protéicas totais.

Considerando ainda o diferencial entre o ganho de peso diário real observado, obtido pela alimentação de acordo com a equação de PB, e o utilizado para predizer as necessidades protéicas, observou-se que apenas na fase de 15 a 20 semanas esse valor foi mais expressivo, indicando que pode ter ocorrido excesso em relação ao preconizado. Mas, como já mencionado anteriormente, o ganho de peso a partir de quatro semanas está mais relacionado à ingestão de EM que de proteína. Assim, o peso corporal não representou bom parâmetro para avaliação da equação de proteína.

\section{Conclusões}

A aplicação das equações de predição das exigências de proteína na alimentação de matrizes pesadas em crescimento, apesar de ter determinado alguns efeitos indesejáveis na conformação de carcaça e composição corporal, indicaram possibilidade na redução dos níveis de proteína nas dietas desde que a qualidade desta proteína seja mantida por meio de suplementação com aminoácidos sintéticos, o que, até o momento, é considerado uma prática economicamente inviável.

\section{Literatura Citada}

BENATTI, M.R.B. Avaliação de equações de predição de exigências energéticas e protéicas na alimentação de frangas de postura. Jaboticabal: Universidade Estadual Paulista, 1998. 71p. Dissertação (Mestrado em Zootecnia) - Universidade Estadual Paulista, 1998.

BONI, I.J. Manejo da maturidade até pico de postura. In: CONFERÊNCIA APINCO DE CIÊNCIA E TECNOLOGIA AVÍCOLA, 1993, Santos. Anais... Santos: 1993. p.83-94.

BOWMAKER, J.E.; GOUS, R.M. Quantification of reproductive changes and nutrient requirements of broiler breeder pullets at sexual maturity. British Poultry Science, v.30, p.663-676, 1989.

CHI, M.S. Effect of low protein diets for growing leghorn pullets upon subsequent laying performance. British Poultry Science, v.26, p.433-440, 1985.

HURWITZ, S.; SKLAN, D.; BARTOV, I. New formal approaches to the determination of energy and amino acid requirements of chicks. Poultry Science, v.57, p.197-205, 1978.

HURWITZ, L.; BORNSTEIN, S. The protein and amino acid requirements of laying hens: suggested models for calculation. Poultry Science, v.52, p.1124-1134, 1973.
LEESON, S.; SUMMERS, J. Commercial poultry nutrition. 2.ed. Ontario: University Books, 1997, 283p.

LEESON, S.; SUMMERS, J.D. Influence of nutritional modification on skeletal size of leghorn and broiler breeder pullets. Poultry Science, v.63, p.1222-1228, 1984.

LILBURN, M.S.; NGIAM-RILLING, K. Dietary effects on body composition and subsequent production characteristics in broiler breeder hens. Poultry Science, v.69, p.11261132, 1990.

LILBURN, M.S.; NGIAM-RILLING, K.; MYERS-MILLER, D.J. Growth and development of broiler breeders. 2 - Independent effects of dietary formulation versus body weight on skeletal and muscle growth. Poultry Science, v.68, p.1274-1281, 1989.

LOPEZ, G.; LEESON, E. Response of broiler breeders to lowprotein diets. 1. Adult breeder performance. Poultry Science, v.74, p.685-695, 1995

McDANIEL, G.R.; BRAKE, J.; ECKMAN, M.K Factors affecting broiler breeders performance. 4 - The interrelationship of some reproductive traits. Poultry Science, v.60, p.1792-1797, 1981.

NATIONAL RESEARCH COUNCIL - NRC. Committee on Animal Nutrition. Subcommittee on Poultry Nutrition. 9.ed. Washington: 1994, 155p.

ROSEBROUGH, R.W.; McMURTRY, J.; STEELE, N. Energy and protein relations inthe broiler. 5. Lipogenesis, glucose production and metabolic hormone levels as function of age and dietary protein levels. Growth, v.51, p.309-320, 1987.

ROSTAGNO, H.S.; SILVA, D.J.; COSTA, P.M.A. et al. Composição de alimentos e exigências nutricionais de aves e suínos (Tabela Brasileira). Viçosa, MG: Universidade Federal de Viçosa, 1983. 59p.

SAKOMURA, N.S. Exigências nutricionais das aves utilizando o método fatorial. In: SIMPÓSIO INTERNACIONAL SOBRE EXIGÊNCIAS NUTRICIONAIS DE AVES E SUÍnOS, 1996, Viçosa, MG. Anais...Viçosa, MG: Universidade Federal de Viçosa, 1996. p.319-344.

SAKOMURA, N.K.; ROSTANGO, H.S.; EUCLIDES, R.F. et al. Determinação das equações de predição da exigência nutricional de energia para matrizes pesadas e galinhas poedeiras. Revista Brasileira de Zootecnia, v.22, n.5, p.723-731, 1993.

SCOTT, M. L.; NESHEIM, M. C.; YOUNG, R. J. Nutrition of the chicken. 3.ed. Ithaca: M.L. Scott \& Ass., 1982. 562p.

SILVA-FILARDI, R.; SAKOMURA, N. K.; BASAGLIA, R. et al. A. Equações de predição das exigências de proteína bruta para matrizes pesadas em crescimento. Revista Brasileira de Zootecnia, v.29, n.6, p.2308-2315, 2000.

WALSH, T.J.; BRAKE, J. The effect of nutrient intake during rearing of broiler breeder females on subsequent fertility, Poultry Science, v.76, p.297-305, 1997. 